\title{
Evaluation of serum uric acid in type two diabetic nephropathy patients
}

\author{
Baviskar P. A ${ }^{1}$, Guha Niyogi NI², V. W Patil ${ }^{3}$, Bagle T. R, $^{4}$ \\ ${ }^{1,2,4}$ Assistant Professor, ${ }^{3}$ Professor, ${ }^{1,2,3}$,Dept. of Biochemistry, ${ }^{4}$ Dept. of Pharmacology, ${ }^{1,4}$ Rajiv Gandhi Medical College \& \\ Chatrapati Shivaji Maharaj Hospital, Thane, Maharashtra, ${ }^{2,3}$ Grant Medical College and Sir Jamshedjee Jeejeebhoy Group of \\ Hospitals, Thane, Maharashtra, India
}

*Corresponding Author: Bagle T. R

Email: tusharbagle21@gmail.com

Accepted: $11^{\text {th }}$ August, 2018

\begin{abstract}
Introduction: Diabetic nephropathy is one of the leading complications of longstanding diabetes mellitus. With the background of inflammation, there is need for laboratory tests for early diagnosis and prevention of diabetic nephropathy.

Materials and Methods: A cross sectional study done after screening, patients satisfying the inclusion and exclusion criteria 50 patients of type II diabetic patients with nephropathy (Group I) and 50 type II diabetic patients without nephropathy(Group II) were included in the study. Serum uric acid was estimated by standard enzymatic uricase method on autoanalyser ADVIA 1800. Serum urea was estimated by urease method and serum creatinine was estimated by Jaffe's method and Sr.Uric Acid by uricase method using fully autoanalyzer ADVIA 1800.

Results: The mean age in group I was $59 \pm 9.28$ years and group II was $56.2 \pm 11.47$ years. The serum Uric Acid was $9.51 \pm 2.46$ $(\mathrm{mg} / \mathrm{dl})$ in group I and statistically significant $(\mathrm{p}<0.001)$ than in group II $5.5 \pm 1.68 \mathrm{mg} / \mathrm{dl}$. The Serum creatinine in group I $(6.68$ $\pm 2.94 \mathrm{mg} / \mathrm{dl})$ and statistically significant $\mathrm{p}<0.001$ as compared to group II $(1.4 \pm 0.77 \mathrm{mg} / \mathrm{dl})$. There was positive correlation between Sr.Uric Acid and Sr. Creatinine ( $r=0.625$, $\mathrm{p}<0.001)$, between Sr.Uric acid and Sr.Urea $(r=0.542$, $p<0.001)$ and between Sr.Uric acid and Sr.FBG $(r=0.841, \mathrm{p}<0.001)$.

Conclusion: Regular detection can help the clinician to take appropriate action to delay complications which in turn may help preserve renal function in DN patients.
\end{abstract}

Keywords: Creatinine, Urea, Fasting blood glucose, Urine albumin.

\section{Introduction}

Diabetes mellitus (DM) is disorder in which there is ineffective glucose metabolism leading to underutilization of glucose. ${ }^{1,2}$ Worldwide prevalence of DM is expected to rise from $8.3 \%$ in 2013 to $10.1 \%$ in 2035.with second largest number of patients of DM expected in India. ${ }^{3,4}$

The metabolic malfunction in DM is responsible for the secondary changes that occur in multiple organ systems. ${ }^{1,2} \mathrm{DN}$ is major cause of morbidity \& mortality in Type 2 DM. $^{5,6}$ In India 30\% chronic renal failures due to diabetic nephropathy (DN). ${ }^{4}$ With longstanding diabetes there is progressive angiopathy of capillaries in glomeruli. ${ }^{6,7}$ Diabetic nephropathy is one of the leading cause of various kidney diseases like end stage of the renal disease and thus where is need of renal replacement therapy. ${ }^{1}$

Serum Uric Acid (UA) in higher levels becomes an injurious factor for the functioning of kidneys. ${ }^{8}$ Hyperuricemia causes endothelial dysfunction and glomerular hypertension thus causing decrease in renal perfusion and subsequent renal failure. ${ }^{9,10}$ Elevated Uric Acid inhibit the expression of Nitric oxide synthase in macula densa that decreases the renin expression from juxtaglomerular cells. ${ }^{11} \mathrm{UA}$ stimulates production of cytokines by leukocytes $\&$ chemokines from vascular smooth muscle cells. ${ }^{12}$ Thus UA is an important parameter that can be used for patients of diabetic nephropathy for treatment monitoring and prognosis.
But there is sparse data available on UA levels in type 2 diabetic nephropathy patients in Indian population, thus the study was done to find the association between serum uric acid, various laboratory parameters in patients having Nephropathy with type 2 DM.

\section{Materials and Methods}

This was a cross sectional study performed in 100 patients in the age of 18-65 years having type $2 \mathrm{DM}$ and attending the Medicine outpatient department of Grant government medical college and Sir Jamshedjee Jeejeebhoy Group of Hospitals, Mumbai. Clinical Institutional Ethics Committee permission for human studies was taken and then the study was started. Study included 50 patients of type II diabetic nephropathy and 50 type II diabetic patients without nephropathy attending Medicine Outpatient department. Written informed consent of the patients was taken and patient information was collected in a proforma. 80 patients of diabetic nephropathy and 72 patients of diabetes were screened out of which 50 patients were included in group I and 50 patients in group II. The inclusion criteria for the study was patient's of both genders, aged 18-65 years, diagnosed as type II diabetes mellitus as per American Diabetes Association (ADA) guidelines. ${ }^{13}$ Patients diagnosed as diabetic nephropathy according to ADA guidelines, blood pressure less than $140 / 90 \mathrm{~mm}$ of $\mathrm{Hg} \cdot{ }^{13}$ The exclusion criteria was type 1 diabetes mellitus, Pregnant women, participants who 
were on dialysis or had a kidney transplant, albuminuria due to causes other than diabetes, patients with severe complications of diabetes mellitus, history of urinary tract infection or pyelonephritis or urinary tract obstruction, history of smoking, alcohol consumption or acute febrile illness, history of gout, intake antiinflammatory drug or allopurinol.

From the patients included in the study approximately 3 to $5 \mathrm{ml}$ of blood was collected after fasting for 10 to 12 hours. The separated serum was used for the estimation of uric acid (Uricase method), urea (urease method) and creatinine (Jaffe's method) by using fully autoanalyzer ADVIA 1800. FBG (Fasting Blood Glucose) and PPBG (Postprandial Blood Glucose) estimation was done by Enzymatic colorimetric method GOD-PAP.

Sample size was calculated using formula (Alpha $=0.05$, beta level $=80 \%$ ) For mean difference in units of Serum Uric Acid $1.5 \mathrm{mg} / \mathrm{dl} .{ }^{8,9} \mathrm{P}<0.05$ was considered to be statistically significant. Groups compared using unpaired $t$ test followed by Welchs Correction. Correlation done by Pearson correlation \& Spearmann correlation test. Statistical analysis was done by Graph Pad version 6.02 statistical software.

\section{Results}

There were 28 males and 22 females in group I while there were 29 males and 21 females in group II. The mean age in group I was $59 \pm 9.28$ years and group II was $56.2 \pm 11.47$ years $(\mathrm{p}=0.182)$. The duration of diabetes in group I was $15.7 \pm 6.11$ years and group II was $6.9 \pm 4.93$ years $(p=0.003)$. Different laboratory parameters in the study are mentioned in table 1.

In group I urine albumin grading there were 23 patients having urine albumin $+1,20$ having urine albumin +2 and 07 having urine albumin +3 . The correlation between sr.uric acid, sr.creatinine is depicted in Fig. 1, correlation of Sr. Uric Acid, Sr.Urea in Fig. 2 and correlation of Sr. Uric Acid and Sr. FBG in Fig. 3. There was no correlation between Sr.uric acid and PPBG, age as well as diabetes duration. In group I, 38 subjects were taking oral hypoglycemic drugs, 12 were taking Insulin and combination of oral hypoglycemic drugs while in group II, 49 were taking oral hypoglycemic drugs and 1 subject was taking insulin as treatment.

Table 1: Laboratory parameters in group I and group II

\begin{tabular}{|l|c|c|c|}
\hline Parameters & $\begin{array}{c}\text { Group I } \\
\text { (Type II diabetic with } \\
\text { Nephropathy) } \\
(\mathrm{n}=50)\end{array}$ & $\begin{array}{c}\text { Group II } \\
\text { (Type II diabetic without } \\
\text { Nephropathy) } \\
(\mathrm{n}=50)\end{array}$ & P value \\
\hline FBG $(\mathrm{mg} / \mathrm{dl})$ & $128.3 \pm 35.77$ & $112.6 \pm 55.53$ & 0.5366 \\
\hline PPBG $(\mathrm{mg} / \mathrm{dl})$ & $215.8 \pm 52.1$ & $202 \pm 83.9$ & 0.5084 \\
\hline Sr. Creatinine $(\mathrm{mg} / \mathrm{dl})$ & $06.68 \pm 2.94$ & $1.4 \pm 0.77$ & $<0.0001^{*}$ \\
\hline Sr. Urea $(\mathrm{mg} / \mathrm{dl})$ & $118.76 \pm 43.49$ & $32.7 \pm 20.81$ & $<0.0001^{*}$ \\
\hline Sr. Uric acid $(\mathrm{mg} / \mathrm{dl})$ & $09.51 \pm 2.46$ & $05.5 \pm 1.68$ & $<0.001^{*}$ \\
\hline
\end{tabular}

*Statistically significant

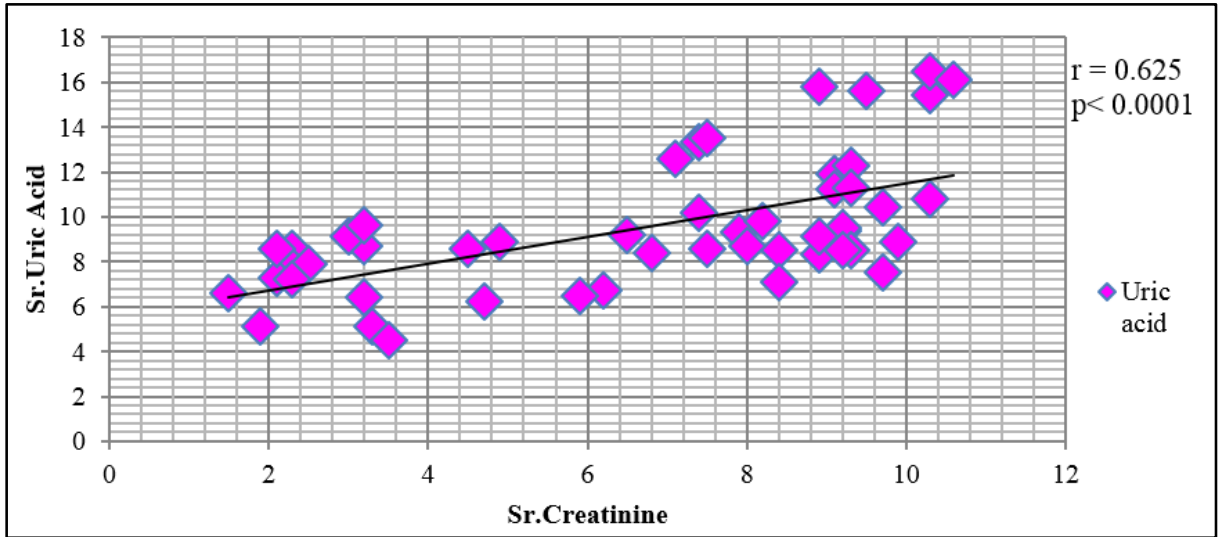

Fig. 1: Correlation between Sr.Uric acid and Sr.Creatinine 


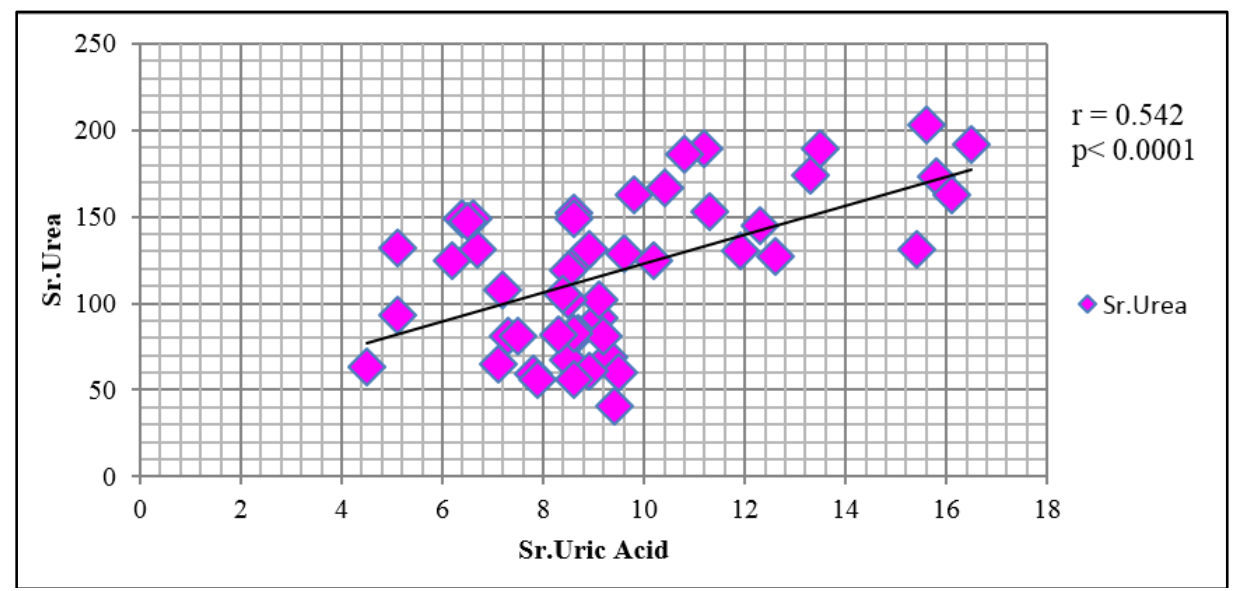

Fig. 2: Correlation between Sr.Uric acid and Sr.Urea

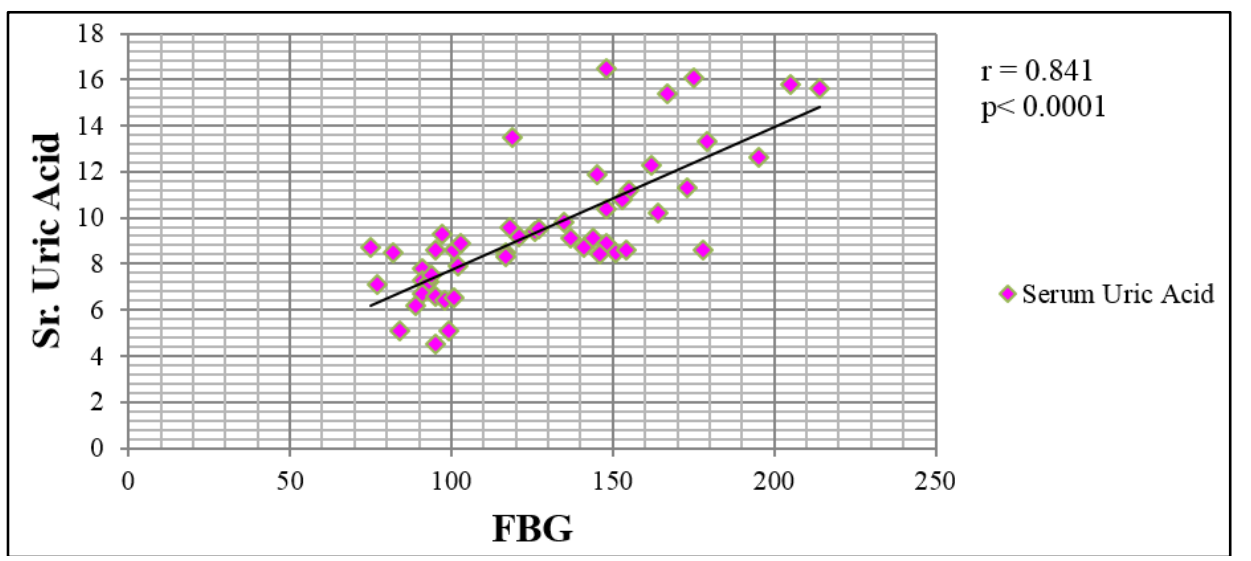

Fig. 3: Correlation between Sr. Uric Acid and Sr. FBG

\section{Discussion}

In our study UA was positively correlated to $\mathrm{Sr}$. Creatinine, FBG and Sr. Urea. Hyperinsulinemia is the basis of type 2 DM pathophysiology. ${ }^{11}$ Biologically, UA has important role in insulin resistance worsening in various models of animals by inhibiting the nitric oxide bioavailability that is important for insulinstimulated glucose uptake ${ }^{1}$. Hyperinsulinemia causes increase reabsorption of uric acid, reduces renal uric acid secretion and also increase production of uric acid. ${ }^{11,12}$ Even though the earliest evidence in DN is appearance of albumin in urine, diabetic patients are more prone to UA injury thus increasing chances of DN. ${ }^{5}$

Patients having higher UA have the ability for more insulin secretion than patients having lower UA. ${ }^{14}$ In study by Zoppini in type 2 diabetic patients hyperuricemia was an independent and important risk factor for development of chronic renal disease ${ }^{15}$ Study by Tanaka showed that UA increase results in declining of renal function in diabetic patients. ${ }^{16}$ Study by Siu had reported that as UA levels were lowered in renal disease patients with hyperuricemia there was associated decrease in kidney disease. ${ }^{17}$

Study by Mahmoud has stated that in patients with renal disease of end stage majority due to diabetis mellitus nephropathy. ${ }^{18}$ Other studies by Sanchez and Momeni have shown that increase in UA and diabetic nephropathy are associated. ${ }^{19,20}$ Study by Neki reveals that levels of UA have linear positive correlation with the amount of proteinurea. Diabetic nephropathy can be suspected by increasing serum uric acid levels and it is seen that UA level correlates well with proteinuria, blood urea and serum creatinine level. ${ }^{21}$

Study by Shokoofen has shown that higher UA levels were associated with an increase in probability of albuminuria in type 2 diabetes mellitus patients. ${ }^{22}$ Study by Tseng has shown UA increases with increase in urine albumin excretion and can be is an independent correlate for urinary albumin Creatinine ratio. ${ }^{23}$ While study by Viazzai had suggested that serum uric acid is predictor that is independent for diabetes mellitus in patients with primary hypertension. ${ }^{24}$ In a study by Saeed UA was positively associated with DN and hypothesized that UA plays a pathological role in the development of DN in type $2 \mathrm{DM}^{25}$

Meta analysis by Kodama suggests that UA is strongly associated with development of DN in type 2 DM regardless of different study characteristics. ${ }^{26}$ Meta-analysis of Lv had cohort studies that showed high level of UA as risk factor that is independent for developing DN in type 2 DM. ${ }^{27}$ 
Study by Jalalhas stated DN as a complex disease. There are various therapeutic options available for the treatment of DN patients but the disease still remains incurable. Various studies had shown evidence to link uric acid directly or indirectly with renal disease progression in type $2 \mathrm{DM}^{28}$ Thus increase in serum uric acid levels in diabetic patients can be used as marker for early detection of nephropathy. Also levels of UA can also be used as marker in severity and treatment of diabetic nephropathy. ${ }^{29}$

\section{Conclusion}

Regular detection can prevent further complications which in turn may help preserve renal function in DN patients. Further research should attempt to determine whether it is effective to utilize UA level as a predictor of type 2 diabetic nephropathy for its prevention.

\section{Acknowledgement}

We would like to acknowledge Dr. J Oglekar V K, Head of Department of Medicine, GGMC and Sir JJ Group of Hospitals, Mumbai.

\section{Conflict of Interest: Nil}

\section{References}

1. Fauci AS, Kasper DS, Longo DL, Braunwald E, Hauser SL, Jameson JL, et al. Harrison's principles of internal medicine. $19^{\text {th }}$ ed. United States; McGraw Hill: 2015.16(3):417.2399-2407.

2. Carl A, Burtis, Edward R. Ashwood David E. Bruns. Tietz Textbook of Clinical Chemistry and Molecular diagnostics. 5th ed. United states; Elsevier: 2012;669708.

3. Guariguata L, Nolan T, Beagley J, Linnenkamp U, Jacqmain O (eds). In: IDF Diabetes Atlas, $6^{\text {th }}$ ed. Belgium. International Diabetes Federation.2013 International diabetes federation. www.idf.org/diabetesatlas. Available from https://www.idf.org/sites/default/files/EN_6E_Atlas_Full _0.pdf https://www.idf.org/component/attachments/attachments. html?id=813\&task=download

4. Ghaffar A, Reddy KS, Singhi M. Burden of noncommunicable diseases in South Asia. BMJ. 2004;328(7443):807-10.

5. American Diabetes Association. Nephropathy in diabetes (Position Statement). Diabetes Care. 2004;27(1):79-83.

6. Pfützner A, Standl E, Strotmann HJ, Schulze J, Hohberg C, Lubben G, et al. Association of high-sensitive Creactive protein with advanced stage beta-cell dysfunction and insulin resistance in patients with type 2 diabetes mellitus. Clin Chem Lab Med. 2006;44(5):556-60.

7. Aronson D. Hyperglycemia and the pathobiology of diabetic complications. Adv Cardiol. 2008;45:1-16.

8. Khosla UM, Zharikov S, Finch JL, Nakagawa T, Roncal $\mathrm{C}, \mathrm{Mu} \mathrm{W}$ et al. Hyperuricemia induces endothelial dysfunction. Kidney Int. 2005;67:1739-42.

9. Iseki K, Ikemiya Y, Inoue T, Iseki C, Kinjo K, Takishita $\mathrm{S}$. Significance of hyperuricemia as a risk factor for developing ESRD in a screened cohort. Am J Kidney Dis. 2004;44:642-50.
10. Sanchez-Lozada LG, Tapia E, Santamaria J, AvilaCasado C, Soto V, Nepomuceno T. Mild hyperuricemia induces vasoconstriction and maintains glomerular hypertension in normal and remnant kidney rats. Kidney Int. 2005;67:237-47.

11. Netea MG, Kullberg BJ, Blok WL, Netea RT, van der Meer JW. The role of hyperuricemia in the increased cytokine production after lipopolysaccharide challenge in neutropenic mice. Blood. 1997.15;89(2):577-82.

12. Kanellis J, Watanabe S, Li JH, Kang DH, Li P, Nakagawa $T$ et al: Uric acid stimulates monocyte chemoattractant protein-1 production in vascular smooth muscle cells via mitogen-activated protein kinase and cyclooxygenase-2. Hypertension. 2003;41:1287-1293.

13. American Diabetes Association. Standards of Medical Care in Diabetes 2014 (Position statement). Diabetes Care. 2014;37(1):14-80.

14. Tang W, Fu Q, Zhang Q, Sun M, Gao Y, Liu X, Qian L, Shan S, Yang T. The Association between Serum Uric Acid and Residual Beta cell function in type 2 Diabetes. Journal of Diabetes Research. 2014;1-9.

15. Zoppini G, Targher G, Chonchol M, Ortalda V, Abaterusso C, Pichiri I, Negri C, Bonora E. Serum Uric Acid Levels and Incident Chronic Kidney Disease in Patients With Type 2 Diabetes and Preserved Kidney Function. Diabetes Care. 2012;35:99-104.

16. Tanaka K, Hara S, Hattori M, Sakai K, Onishi Y, Yoshida Y, et al. Role of elevated serum uric acid levels at the onset of overt nephropathy in the risk for renal function decline in patients with type 2 diabetes. Journal of Diabetes Investigation. 2015;6(1):98-104.

17. Siu YP, Leung KT, Tong MK, Kwan TH. Use of allopurinol in slowing the progression of renal disease through its ability to lower serum uric acid level. Am J Kidney Dis. 2006;47:51-9.

18. Mahmoud RK, Saeed B, Soleiman K, Nasri H.Association of Serum Uric Acid With Level of Blood Pressure in Type 2 Diabetic Patients. Iranian Journal of Kidney Diseases. 2014;8(2):152-154.

19. Sanchez-Lozada LG, Soto V, Tapia E, Avila-Casado C, Sautin YY, Nakagawa T, et al. Role of oxidative stress in the renal abnormalities induced by experimental hyperuricemia. Am J Physiol Renal Physiol. 2008;295:F1134-F1141.

20. Momeni A. Serum Uric Acid and diabetic nephropathy. Journal of Renal Injury prevention. 2012;1(1):37-38.

21. Neki NS, Gupta H, Eeena RM, Mani T. A Study of Association of Hyperuricemia with Progressive Diabetic Nephropathy. Journal of International Medical Sciences Academy. 2015;28(1):11-12.

22. Shokoofeh B, Hami M, Shakeri MT. Hyperuricemia and Albuminuria in Patients With Type 2 Diabetes Mellitus. Iranian Journal of Kidney Diseases. 2011;5(1):21-24.

23. Tseng $\mathrm{CH}$. Correlation of uric acid and urinary albumin excretion rate in patients with type 2 diabetes mellitus in Taiwan. Kidney International. 2005;68:796-801.

24. Viazzi F, Leoncini G, Vercelli M, Deferrari G, Pontremoli R. Serum Uric Acid Levels Predict NewOnset Type 2 Diabetes in Hospitalized Patients With Primary Hypertension: The MAGIC Study. Diabetes Care. 2011;34:126-128.

25. Saeed B, Mohammad KH, Azar B, Hamid N. Association of serum uric acid with proteinuria in type 2 diabetic patients. J Res Med Sci. 2013;18(1):44-46.

26. Kodama S, Saito K, Yachi Y, Asumi M, Sugawara A, Totsuka K, Saito A, Sone H. Association between serum uric acid and development of type 2 diabetes. Diabetes Care. 2009;32(9):1737-42. 
27. Lv Q, Meng XF, He FF, Chen S, Su H, Xiong J. High serum uric acid and increased risk of type 2 diabetes: a systemic review and meta-analysis of prospective cohort studies. PLoS One. 2013;8(2):e56864.

28. Jalal DI, Maahs DM, Hovind P, Nakagawa T. Uric acid as a mediator of diabetic nephropathy. Semin Nephrol. 2011;31(5):459-65.

29. Jung Eun Lee, Yoon-Goo Kim, Yoon-Ho Choi, Wooseong Huh, Dae Joong Kim and Ha Young Oh. Serum Uric Acid Is Associated With Microalbuminuria in Prehypertension. Hypertension. 2006;47:962-67.

How to cite this article: Baviskar P. A, Guha N. N, Patil V. W, Bagle T. R. Evaluation of serum uric acid in type two diabetic nephropathy patients. Int $\mathrm{J}$ Clin Biochem Res. 2018;5(4):608-612. 